\title{
Simplifying the assessment of parameters of electron-transfer reactions by using easy-to-use thin-layer spectroelectrochemistry devices
}

\author{
Jesus Garoz-Ruiz ${ }^{1}$, Carlos Guillen-Posteguillo ${ }^{1,2}$, Aranzazu Heras*, Alvaro Colina* \\ Department of Chemistry, Universidad de Burgos, Pza. Misael Bañuelos s/n, E-09001 Burgos, Spain
}

\section{E-mail addresses:}

Jesus Garoz-Ruiz: _ jgarozruiz@ubu.es

Carlos Guillen-Posteguillo: ～CXG623@student.bham.ac.uk

Aranzazu Heras: _ maheras@ubu.es

Alvaro Colina: _ acolina@ubu.es

\section{* Corresponding authors:}

maheras@ubu.es / acolina@ubu.es. Tel.: +34 947258817. Fax: +34 947258831.

\section{Author contributions:}

${ }^{1}$ These authors contributed equally to this work. 


\section{Present address:}

\footnotetext{
${ }^{2}$ School of Chemistry, University of Birmingham, Edgbaston B15 2TT, U.K.
}

\section{Abstract}

UV-Vis absorption thin-layer spectroelectrochemistry greatly contributes to the assessment of parameters of electron-transfer reactions by means of electrochemical and spectroscopic information obtained simultaneously in a confined space around the working electrode. In this work we present an ingenious modification of a spectroelectrochemistry device based on carbon nanotubes and bare optical fibers to perform UV-Vis absorption thin-layer spectroelectrochemistry measurements. Working and counter electrodes are made of carbon nanotubes filtered and press-transferred onto a flat support where a painted silver line acts as pseudo-reference electrode. To perform high sensitivity measurements, two optical fibers are fixed to the support in parallel arrangement. As a novelty, a quartz plate is placed on top of the optical fibers in order to create a thin-layer whose thickness is reproducibly controlled by the diameter of the optical fibers. This methodology is also successfully applied using commercial screenprinted electrodes. Three different electroactive compounds, ferrocenemethanol, otolidine and $\mathrm{Ru}(\text { bipy })_{3}{ }^{2+}$, are studied and good results are obtained. As demonstrated below, these long optical path UV-Vis absorption thin-layer spectroelectrochemistry cells considerably reduce the complexity associated with this type of devices, eliminating one of the major disadvantages of this technique and making it much more accessible to the scientific community. 
Keywords: thin-layer; spectroelectrochemistry; bare optical fibers; carbon nanotubes; screen-printed electrodes.

\section{Introduction}

One of the main aims of chemistry is the development of new compounds with outstanding properties. Evidently, a thorough characterization of these substances is necessary before their use. As far as electrochemical properties are concerned, spectroelectrochemistry (SEC) techniques [1], particularly thin-layer SEC, can significantly help to assess several parameters of compounds that undergo electrontransfer reactions [2].

UV-Vis absorption thin-layer SEC is a powerful hybrid technique that allows the researcher to simultaneously obtain electrochemical and spectroscopic responses of a chemical system in the few micrometers of the confined solution adjacent to the surface of the working electrode (WE) [3-5]. When the light beam travels in perpendicular direction with respect to the WE surface in normal configuration [6,7], it collects information about the solution and the WE. However, when the light beam is parallel to the WE, parallel arrangement [8], only the solution is sampled. As can be expected, bidimensional thin-layer SEC, the simultaneous performance of normal and parallel SEC, combines the best features of both arrangements [9]. The advantages provided by UV-Vis absorption thin-layer SEC have been exploited in multiple research fields, including side-reactions [2,10], self-assembled monolayers [11], compounds of biological interest [12-16], photovoltaic cells [17], optoelectronics [18], conducting 
polymers [19,20], corrosion phenomena [21], porphyrins [22] and metal complexes [23-27].

The use of carbon materials in electrochemistry is rapidly increasing [28-30]. For instance, the growing importance of carbon nanotubes (CNTs) is explained by the remarkable properties that this carbon allotrope possesses [31-33]. In a previous work, we developed a methodology based on filtering a dispersion of CNTs [34] that enables us to transfer homogeneous CNTs films on different supports [34-37]. These CNTs electrodes have demonstrated an excellent performance as optically transparent electrodes [34,36] and for the quantitative determination of analytes [35,37].

Several devices, some of which are cited in this contribution, have been widely used and have laid the groundwork for numerous UV-Vis absorption thin-layer SEC research studies. Nevertheless, it should be noted that the complexity of the existing UV-Vis absorption thin-layer SEC cells is one of their most important drawbacks so far. On the one hand, normal transmission arrangement needs optically transparent electrodes, drastically reducing the number of electrodes that can be used. On the other hand, a perfect but difficult alignment of the light beams is required in parallel configuration. In practice, this means that many different parts must be duly assembled to carry out a single experiment. To overcome these problems, we are going to focus on two facts that, in recent years, have drawn great interest in this research field: (i) the use of CNTs networks $[38,39]$ and (ii) the use of optical fibers in long optical path cells whose origin, curiously, can actually date back to the early 1980s [40].

In this paper we develop an easy-to-use device to perform UV-Vis absorption thin-layer SEC experiments in a friendly way, based on CNTs electrodes and bare optical fibers set in parallel configuration, allowing us to work with both transparent and non- 
transparent WEs. The thickness of the thin-layer is solely controlled by three optical fibers and the use of a quartz plate on them. The distance between the optical fibers carrying light determines the length of the optical path, allowing us to study electroactive compounds with very different molar absorption coefficients and to have high sensitivity. The other optical fiber is only used as a spacer. Although the main focus is on the use of CNTs as electrode material, our methodology has also been applied using commercial carbon screen-printed electrodes (SPEs). The cells have been tested with ferrocenemethanol (FcMeOH), o-tolidine, and Ru(bipy) ${ }_{3}{ }^{2+}$. The main electrochemical parameters of their electrochemical reactions (formal potential and electrons transferred) have been properly assessed.

\section{Experimental}

\subsection{Reagents and materials}

Single-walled carbon nanotubes (SWCNTs, Sigma-Aldrich), 1,2-dichloroethane (DCE, 99.8\%, for HPLC, Acros Organics), polytetrafluoroethylene membranes (filter pore size $0.1 \mu \mathrm{m}$, JVWP01300, Millipore Omnipore), polyethylene terephthalate (PET, $175 \mu \mathrm{m}$ thick, HiFi Industrial Film), silver conductive paint (Electrolube) and transparent nail polish (Essence) were used to fabricate the electrodes based on CNTs. Carbon SPEs (DRP-110, DropSens) were used as commercial electrodes. Three bare optical fibers (100 $\mu \mathrm{m}$ in diameter, Ocean Optics) and a quartz plate (Sugelabor) were required to develop the UV-Vis absorption thin-layer SEC devices. FcMeOH (97\%, Acros Organics), o-tolidine (Aldrich Chemical Company, Inc.), Ru(bipy) ${ }_{3}{ }^{2+}$ (Tris(2,2'bipyridyl)ruthenium(II) chloride, hexahydrate, 98\%, Acros Organics), KCl (Acros 
Organics), acetic acid (VWR) and $\mathrm{HClO}_{4}(60 \%$, Panreac) were used to prepare the solutions. All reagents were used as received without further purification. All chemicals were of analytical grade. Aqueous solutions were freshly prepared using high purity water (18.2 $\mathrm{M} \Omega \mathrm{cm}$ resistivity at $25^{\circ} \mathrm{C}$, Milli-Q Direct 8, Millipore). All handling and processing were performed carefully, particularly when DCE was used.

\subsection{Instrumentation}

SEC set-up included a potentiostat/galvanostat (PGSTAT302N, Metrohm Autolab), a halogen-deuterium light source (AvaLight-DH-S-BAL, Avantes) and a spectrometer (QE65000, 198-1006 nm, Ocean Optics). Stencils were made of poly(methyl methacrylate) (Maniplastic) using a $\mathrm{CO}_{2}$ laser cutting machine. A tip-sonicator (CY500, Optic ivymen System) and a laboratory hydraulic press (SpectroPress, Chemplex Industries, Inc.) were also used in this work.

\subsection{Fabrication of the long optical path UV-Vis absorption thin-layer SEC devices}

The development of the present cells is based on a previous design of our group devised to carry out quantitative SEC analysis in a semi-infinite diffusion regime [37], which has been ingeniously adapted to develop the thin-layer SEC devices presented in the current work. Briefly, $2 \mathrm{~mL}$ of a sonicated SWCNTs dispersion were filtered and the homogeneous SWCNTs film deposited on the membrane was press-transferred on a PET support using a stencil with the desired shape. This methodology, which allows us to fabricate a three-electrode cell with a WE and a counter electrode (CE) of SWCNTs and a Ag pseudo-reference electrode (RE) made with silver conductive paint, is optimal 
to have the three electrodes completely flat on the support and to remove the typically large RE and CE. Electrical contacts were made with silver conductive paint and were electrically isolated using nail polish. Afterwards, two $100 \mu \mathrm{m}$ bare optical fibers were aligned opposite one another and fixed to the PET support with nail polish, taking care that the bare optical fibers were not covered with this adhesive. A cello tape can also be used for this purpose in the development of this device. Misalignment of the optical fibers separated by a gap causes significant losses in the amount of collected light and, consequently, a deterioration of the signal/noise ratio. For this reason, the procedure used to perfectly align the bare optical fibers, with their ends touching partially the WE surface, consisted of pressing them towards the support while looking for the largest number of photons that arrive to the detector. When the nail polish was totally dried, a drop of only $20 \mu \mathrm{L}$ of solution was deposited on the WE after homogenization.

Subsequently, in order to establish the thin-layer diffusion regime, a quartz plate was simply placed on top of the optical fibers, pressing the drop between the support and the quartz plate and covering the three electrodes and the ends of the optical fibers with the sample solution. A spacer bare optical fiber was also placed before this last step to ensure the parallelism of the PET slide and the quartz plate. In this particular way, the assembly is extremely easy. Although other materials could be used, the quartz plate was selected due to its relatively high weight that helps to establish the thin-layer and to its transparency that enables us to observe the system. It should be noted that this quartz plate enables us to work in normal or even in bidimensional arrangement. Fig. 1A illustrates this UV-Vis absorption thin-layer SEC device based on CNTs electrodes. It can be noticed that the optical fibers in parallel configuration with respect to the WE control both the optical path length (distance between the optical fibers) and the thinlayer thickness which is actually the optical fibers diameter (ca. $140 \mu \mathrm{m}$ due to the 
cladding material). Finally, one of the optical fibers was connected to the light source and the other to the monochromator/detector, and the electrical contacts to the potentiostat.

Although the method for fabricating this device based on CNTs electrodes is simple and available to all laboratories, we have applied our methodology to the use of commercial SPEs. By fixing the bare optical fibers directly to a carbon SPE using nail polish and employing the same quartz plate as before, we can successfully reproduce the thin-layer thickness, incredibly increasing the ease of performing the measurements (Fig. 1B). As is supposed, this fact demonstrates that our cell geometries do not require optically transparent electrodes, being very interesting for opaque materials.

Several advantages of these original SEC cells should be highlighted, as, for example, the possibility of using non-transparent electrodes, the increase of the sensitivity due to the long optical path length and the excellent potential/time and spectral resolution (see Fig. 1C to follow the spectra evolution with potential/time recorded during a cyclic voltammetry of Ru(bipy) ${ }_{3}{ }^{2+}$ ). We must emphasize, particularly, the ease of performing UV-Vis absorption thin-layer SEC measurements and the simplicity of controlling both the optical path length and the thin-layer thickness.

\section{Results and discussion}

FcMeOH, $o$-tolidine and $\mathrm{Ru}(\mathrm{bipy})_{3}{ }^{2+}$ were used to evaluate the performance of the UVVis absorption thin-layer SEC devices presented herein. The electrical signal was recorded concomitantly with the UV-Vis spectral changes that take place in the first micrometers adjacent to the WE surface. The cyclic voltammograms are shown in Fig. 
2A and the corresponding cyclic voltabsorptograms at the selected wavelengths are plotted in Fig. 2B. In all cases, the integration time for the spectrometer was $300 \mathrm{~ms}$ and the initial solution with the electroactive compound was taken as reference spectrum. The step potential was set at $0.01 \mathrm{~V}$ in order to reach a steady-state at every applied potential under finite diffusion conditions.

FcMeOH is an electroactive compound commonly used as a redox couple $\left(\mathrm{FcMeOH}^{+} / \mathrm{FcMeOH}\right)$ probe that allows us to validate SEC set-ups [36,37]. As is known, it undergoes a simple, well-defined, one-electron chemically reversible electrochemical process in a diffusion-controlled way. A cyclic voltammetry of $5 \cdot 10^{-4}$ $\mathrm{M} \mathrm{FcMeOH}$ in $0.1 \mathrm{M} \mathrm{KCl}$ was performed between $+0.05 \mathrm{~V}$ and $+0.23 \mathrm{~V}$ at a potential scan rate of $0.001 \mathrm{~V} \cdot \mathrm{s}^{-1}$ (blue curve of Fig. 2A), using the device based on CNTs electrodes. The peak potential difference is around $0.040 \mathrm{~V}$. As previously reported $[36,37]$, the spectra evolution with potential exhibits the changes in three UV-Vis absorption bands at 260, 282 and $630 \mathrm{~nm}$. The corresponding cyclic voltabsorptogram at $282 \mathrm{~nm}$ (blue curve of Fig. 2B) clearly shows that the absorbances of the anodic and cathodic scans are practically overlapped (10 $\mathrm{mV}$ separation), demonstrating the great performance of the UV-Vis absorption thin-layer SEC cell and the excellent electrochemical reversibility of FcMeOH. As can be observed, a maximum absorbance value is reached at the highest potential, indicating the total electrolysis of FcMeOH. Using the Nernst equation together with the Beer-Lambert law, Eq. (1), a formal potential of $E^{0^{\prime}}=+0.149 \mathrm{~V}$ (repeatability, $\mathrm{RSD}_{\mathrm{n}=5}=4.41 \%$; reproducibility, $\mathrm{RSD}_{\mathrm{n}=3}=1.24 \%$ ) and a number of electrons transferred of $n=1.01$ (repeatability, $\mathrm{RSD}_{\mathrm{n}=5}=3.59 \%$; reproducibility, $\mathrm{RSD}_{\mathrm{n}=3}=2.08 \%$ ) are obtained, in agreement with the expected values. 
$E=E^{0^{\prime}}-2.3 \frac{R T}{n F} \log \frac{A_{R e d}-A}{A-A_{O x}}$

The redox behavior of $o$-tolidine at very acidic $\mathrm{pH}$ is similar to the previous one, but in this case $o$-tolidine undergoes a two-electron transfer reaction to the corresponding quinonediimine $[41,42]$. A cyclic voltammetry of $4 \cdot 10^{-5} \mathrm{M} o$-tolidine in $0.5 \mathrm{M}$ acetic acid and $1 \mathrm{M} \mathrm{HClO}_{4}$ was carried out between $+0.15 \mathrm{~V}$ and $+0.35 \mathrm{~V}$ at a potential scan rate of $0.0005 \mathrm{~V} \cdot \mathrm{s}^{-1}$ (green curve of Fig. 2A), using the device based on CNTs electrodes. The experimental scan rate is lower than in the previous case; however, it should be noted that, depending on the application, wider or narrower optical fibers can be used. The peak potential difference is around $0.03 \mathrm{~V}$. The spectra evolution with time/potential exhibits the changes in a well-defined absorption band at $437 \mathrm{~nm}[41,42]$. The corresponding cyclic voltabsorptogram at this wavelength (green curve of Fig. 2B) indicates that the absorbances of the forward and backward sweeps are completely overlapped (5 mV separation). The electrochemical parameters of this electron-transfer reaction are properly assessed, obtaining a value of $E^{0^{\prime}}=+0.275 \mathrm{~V}$ for the formal potential (repeatability, $\mathrm{RSD}_{\mathrm{n}=3}=7.20 \%$; reproducibility, $\mathrm{RSD}_{\mathrm{n}=2}=3.95 \%$ ) and a value of $n=1.99$ for the number of electrons transferred (repeatability, $\mathrm{RSD}_{\mathrm{n}=3}=8.49 \%$; reproducibility, $\mathrm{RSD}_{\mathrm{n}=2}=1.95 \%$ ), which are again consistent with the expected values. Finally, the device based on a carbon SPE has been applied to the study of Ru(bipy) ${ }_{3}{ }^{2+}$, a redox probe $\left(\mathrm{Ru}(\mathrm{bipy})_{3}{ }^{3+/ 2+}\right)$ that is oxidized at a very high potential [38]. A cyclic voltammetry of $5 \cdot 10^{-4} \mathrm{M} \mathrm{Ru}\left(\right.$ bipy) ${ }_{3}{ }^{2+}$ in $0.2 \mathrm{M} \mathrm{KCl}$ was performed between $+0.80 \mathrm{~V}$ and $+1.20 \mathrm{~V}$ at a potential scan rate of $0.001 \mathrm{~V} \cdot \mathrm{s}^{-1}$ (red curve of Fig. 2A). As can be seen in this figure, the electrochemical response is really poor due to the presence of capacitive processes at these high potentials, being very difficult to obtain information such as the peak potential difference from the cyclic voltammogram. The corresponding 
cyclic voltabsorptogram, plotted at a wavelength of $310 \mathrm{~nm}$ (red curve of Fig. 2B), constitutes a better analytical signal because the absorbance is not affected by nonfaradaic processes, demonstrating the powerful advantages of spectroelectrochemistry. Although the absorption band most commonly employed to follow this compound is the one at $452 \mathrm{~nm}$ (see Fig. 1C), we have selected $310 \mathrm{~nm}$ because is not easy to follow the spectral changes in the UV region, demonstrating the excellent performance of our devices. The spectral changes at this wavelength confirm the electrochemical reversibility because the absorbance values of the anodic and cathodic scans are totally overlapped (5 mV separation). A formal potential of $E^{0^{\prime}}=+1.019 \mathrm{~V}$ (repeatability, $\mathrm{RSD}_{\mathrm{n}=3}=0.81 \%$; reproducibility, $\mathrm{RSD}_{\mathrm{n}=3}=1.15 \%$ ) and a number of electrons transferred of $n=0.94$ (repeatability, $\mathrm{RSD}_{\mathrm{n}=3}=1.48 \%$; reproducibility, $\mathrm{RSD}_{\mathrm{n}=3}=3.02 \%$ ) are obtained, which agree with the expected values.

To summarize this section, the UV-Vis absorption thin-layer SEC devices fabricated in the present work allows us to assess the main parameters of electron-transfer reactions in an easy way, showing the potential of our methodology based on optical fibers with both CNTs electrodes and commercial SPEs.

\section{Conclusions and future work}

In this paper we have developed novel devices that represent a significant advance for the performance of UV-Vis absorption thin-layer SEC measurements in an inexpensive, quick and friendly way. These cells, based on bare optical fibers in parallel configuration with CNTs electrodes or commercial SPEs, remarkably reduce the complexity associated with this type of devices, one of the major drawbacks of this 
technique until now. Furthermore, the long optical path offers high sensitivity. The optical fibers, which are fixed to the support, play the following key roles: (i) to conduct the parallel light beam through the first micrometers of the solution adjacent to the WE surface; (ii) to establish the optical path length; and (iii) to control the thin-layer thickness by using a quartz plate placed on top of them. The good performance of these cells has been evaluated with FcMeOH, o-tolidine and $\mathrm{Ru}($ bipy $){ }_{3}{ }^{2+}$. The main parameters of their electron-transfer reactions have been properly assessed.

Additionally, the reduced size of the cell (only $2 \mathrm{~cm}$ wide) will enable us to place it in a sealed chamber to perform experiments in the absence of oxygen, an essential requirement for several applications. Furthermore, the design based on CNTs electrodes allows us to use it in other media, for example organic solvents, by replacing the nail polish by another insulator. Besides, the design based on SPEs has only the own limitations of this commercial material. Finally, the presence of the quartz plate, an optically transparent material in the whole UV-Vis spectrum, suggests the possibility of using this device to perform normal and bidimensional spectroelectrochemistry experiments in a near future.

These UV-Vis absorption thin-layer SEC devices open new avenues for studying many different chemical systems and are definitely capable of helping researchers to obtain interesting results in different electrochemical fields in a fast and simple way.

\section{Acknowledgements}

Support from Ministerio de Economía y Competitividad (CTQ2014-55583-R, CTQ2014-61914-EXP, CTQ2015-71955-REDT) and Junta de Castilla y León (BU033- 
U16) is gratefully appreciated. J. Garoz-Ruiz greatly acknowledges his FPU fellowship

from Ministerio de Educación, Cultura y Deporte (FPU12/02795) and his postdoctoral

contract from Ministerio de Economía y Competitividad (CTQ2014-55583-R).

\section{References}

[1] T. Kuwana, R.K. Darlington, D.W. Leedy, Electrochemical Studies Using Conducting Glass Indicator Electrodes, Anal. Chem. 36 (1964) 2023-2025. doi:10.1021/ac60216a003.

[2] A. Heras, A. Colina, V. Ruiz, J. López-Palacios, UV-Visible Spectroelectrochemical Detection of Side-Reactions in the Hexacyanoferrate(III)/(II) Electrode Process, Electroanalysis 15 (2003) 702-708. doi:10.1002/elan.200390088.

[3] W.R. Heineman, Spectroelectrochemistry: The combination of optical and electrochemical techniques, J. Chem. Educ. 60 (1983) 305-308. doi:10.1021/ed060p305.

[4] T.E. Keyes, R.J. Forster, Spectroelectrochemistry, in: C.G. Zoski (Ed.), Handbook of Electrochemistry, Elsevier, Amsterdam, 2007, pp. 591-635. doi:10.1016/B978-0444519580.50027-6.

[5] W. Kaim, J. Fiedler, Spectroelectrochemistry: the best of two worlds, Chem. Soc. Rev. 38 (2009) 3373-3382. doi:10.1039/b504286k.

[6] C.A. Schroll, S. Chatterjee, W.R. Heineman, S.A. Bryan, Thin-Layer Spectroelectrochemistry on an Aqueous Microdrop, Electroanalysis 24 (2012) 1065-1070. doi:10.1002/elan.201100711.

[7] P.A. Flowers, D.A. Blake, Submicroliter Electrochemistry and Spectroelectrochemistry Using Standard Electrodes and a Polymer Electrolyte Salt Bridge, Anal. Chem. 85 (2013) 3059-3063. doi:10.1021/ac303712v.

[8] D. Daniel, I.G.R. Gutz, Long-Optical-Path Thin-Layer Spectroelectrochemical Flow Cell with Inexpensive Gold Electrodes, Electroanalysis 13 (2001) 681-685. doi:10.1002/15214109(200105)13:8/9<681::AID-ELAN681>3.0.CO;2-F.

[9] J. López-Palacios, A. Colina, A. Heras, V. Ruiz, L. Fuente, Bidimensional Spectroelectrochemistry, Anal. Chem. 73 (2001) 2883-2889. doi:10.1021/ac0014459.

[10] J. López-Palacios, A. Heras, Á. Colina, V. Ruiz, Bidimensional spectroelectrochemical study on electrogeneration of soluble Prussian Blue from hexacyanoferrate(II) solutions, Electrochim. Acta 49 (2004) 1027-1033. doi:10.1016/j.electacta.2003.10.013. 
[11] O. Alévêque, E. Levillain, L. Sanguinet, Spectroelectrochemistry on electroactive self-assembled monolayers: Cyclic voltammetry coupled to spectrophotometry, Electrochem. Commun. 51 (2015) 108-112. doi:10.1016/j.elecom.2014.12.014.

[12] D. Moss, E. Nabedryk, J. Breton, W. Mäntele, Redox-linked conformational changes in proteins detected by a combination of infrared spectroscopy and protein electrochemistry. Evaluation of the technique with cytochrome c, Eur. J. Biochem. 187 (1990) 565-572. doi:10.1111/j.14321033.1990.tb15338.x.

[13] J.-B. He, Y. Wang, N. Deng, X.-Q. Lin, Study of the adsorption and oxidation of antioxidant rutin by cyclic voltammetry-voltabsorptometry, Bioelectrochemistry 71 (2007) 157-163. doi:10.1016/j.bioelechem.2007.03.003.

[14] A. Nakamura, T. Suzawa, Y. Kato, T. Watanabe, Species Dependence of the Redox Potential of the Primary Electron Donor P700 in Photosystem I of Oxygenic Photosynthetic Organisms Revealed by Spectroelectrochemistry, Plant Cell Physiol. 52 (2011) 815-823. doi:10.1093/pcp/pcr034.

[15] E.L. D’Antonio, E.F. Bowden, S. Franzen, Thin-layer spectroelectrochemistry of the $\mathrm{Fe}(\mathrm{III}) / \mathrm{Fe}(\mathrm{II})$ redox reaction of dehaloperoxidase-hemoglobin, J. Electroanal. Chem. 668 (2012) 37-43. doi:10.1016/j.jelechem.2011.12.015.

[16] R. Sokolová, J.E. Nycz, Š. Ramešová, J. Fiedler, I. Degano, M. Szala, V. Kolivoška, M. Gál, Electrochemistry and Spectroelectrochemistry of Bioactive Hydroxyquinolines: A Mechanistic Study, J. Phys. Chem. B 119 (2015) 6074-6080. doi:10.1021/acs.jpcb.5b00098.

[17] D.L. Vangeneugden, D.J.M. Vanderzande, J. Salbeck, P.A. van Hal, R.A.J. Janssen, J.C. Hummelen, C.J. Brabec, S.E. Shaheen, N.S. Sariciftci, Synthesis and Characterization of a Poly(1,3-dithienylisothianaphthene) Derivative for Bulk Heterojunction Photovoltaic Cells, J. Phys. Chem. B 105 (2001) 11106-11113. doi:10.1021/jp013073t.

[18] S.J. Yeh, C.Y. Tsai, C.-Y. Huang, G.-S. Liou, S.-H. Cheng, Electrochemical characterization of small organic hole-transport molecules based on the triphenylamine unit, Electrochem. Commun. 5 (2003) 373-377. doi:10.1016/S1388-2481(03)00072-9.

[19] V. Ruiz, Á. Colina, A. Heras, J. López-Palacios, R. Seeber, Bidimensional chronoabsorptometric study of electropolymerisation of 4,4'-bis(2-methylbutylthio)-2,2'-bithiophene, Electrochem. Commun. 4 (2002) 451-456. doi:10.1016/S1388-2481(02)00325-9.

[20] J. López-Palacios, E. Muñoz, M.A. Heras, Á. Colina, V. Ruiz, Study of polyaniline films degradation by thin-layer bidimensional spectroelectrochemistry, Electrochim. Acta 52 (2006) 234-239. doi:10.1016/j.electacta.2006.04.061.

[21] Y.-H. Wang, J.-B. He, Corrosion inhibition of copper by sodium phytate in NaOH solution: Cyclic voltabsorptometry for in situ monitoring of soluble corrosion products, Electrochim. Acta 66 (2012) 45-51. doi:10.1016/j.electacta.2012.01.063.

[22] K.M. Kadish, P. Chen, Y.Y. Enakieva, S.E. Nefedov, Y.G. Gorbunova, A.Y. Tsivadze, A. Bessmertnykh-Lemeune, C. Stern, R. Guilard, Electrochemical and spectroscopic studies of poly(diethoxyphosphoryl)porphyrins, J. Electroanal. Chem. 656 (2011) 61-71. doi:10.1016/j.jelechem.2011.01.011.

[23] D. Schweinfurth, N. Büttner, S. Hohloch, N. Deibel, J. Klein, B. Sarkar, Heterobimetallic Cu$\operatorname{dppf}($ dppf = 1,1'-Bis(diphenylphosphino)ferrocene) Complexes with “Click” Derived Ligands: A Combined Structural, Electrochemical, Spectroelectrochemical, and Theoretical Study, Organometallics 32 (2013) 5834-5842. doi:10.1021/om400429f. 
[24] U. Pfaff, A. Hildebrandt, D. Schaarschmidt, T. Rüffer, P.J. Low, H. Lang, Molecular Wires using (Oligo)pyrroles as Connecting Units: An Electron Transfer Study, Organometallics 32 (2013) 6106-6117. doi:10.1021/om4007533.

[25] A. Mandal, T. Kundu, F. Ehret, M. Bubrin, S.M. Mobin, W. Kaim, G.K. Lahiri, Varying electronic structural forms of ruthenium complexes of non-innocent 9,10-phenanthrenequinonoid ligands, Dalt. Trans. 43 (2014) 2473-2487. doi:10.1039/C3DT53104J.

[26] A. Paretzki, M. Bubrin, J. Fiedler, S. Záliš, W. Kaim, Correlated Coordination and Redox Activity of a Hemilabile Noninnocent Ligand in Nickel Complexes, Chem. - A Eur. J. 20 (2014) 5414-5422. doi:10.1002/chem.201304316.

[27] J. Tory, L. King, A. Maroulis, M. Haukka, M.J. Calhorda, F. Hartl, Solvent-Dependent Formation of Os(0) Complexes by Electrochemical Reduction of [Os(CO)(2,2'-bipyridine)(L)Cl2]; L = Cl-, PrCN, Inorg. Chem. 53 (2014) 1382-1396. doi:10.1021/ic402146t.

[28] R.L. McCreery, Advanced Carbon Electrode Materials for Molecular Electrochemistry, Chem. Rev. 108 (2008) 2646-2687. doi:10.1021/cr068076m.

[29] K. Scida, P.W. Stege, G. Haby, G.A. Messina, C.D. García, Recent applications of carbon-based nanomaterials in analytical chemistry: Critical review, Anal. Chim. Acta 691 (2011) 6-17. doi:10.1016/j.aca.2011.02.025.

[30] X. Mao, G.C. Rutledge, T.A. Hatton, Nanocarbon-based electrochemical systems for sensing, electrocatalysis, and energy storage, Nano Today 9 (2014) 405-432.

doi:10.1016/j.nantod.2014.06.011.

[31] C.E. Banks, R.G. Compton, New electrodes for old: from carbon nanotubes to edge plane pyrolytic graphite, Analyst 131 (2006) 15-21. doi:10.1039/B512688F.

[32] P. Yáñez-Sedeño, J.M. Pingarrón, J. Riu, F.X. Rius, Electrochemical sensing based on carbon nanotubes, TrAC Trends Anal. Chem. 29 (2010) 939-953. doi:10.1016/j.trac.2010.06.006.

[33] J.C. Byers, A.G. Güell, P.R. Unwin, Nanoscale electrocatalysis: Visualizing oxygen reduction at pristine, kinked, and oxidized sites on individual carbon nanotubes, J. Am. Chem. Soc. 136 (2014) 11252-11255. doi:10.1021/ja505708y.

[34] J. Garoz-Ruiz, S. Palmero, D. Ibañez, A. Heras, A. Colina, Press-transfer optically transparent electrodes fabricated from commercial single-walled carbon nanotubes, Electrochem. Commun. 25 (2012) 1-4. doi:10.1016/j.elecom.2012.09.004.

[35] J. Garoz-Ruiz, D. Izquierdo, A. Colina, S. Palmero, A. Heras, Optical fiber spectroelectrochemical device for detection of catechol at press-transferred single-walled carbon nanotubes electrodes, Anal. Bioanal. Chem. 405 (2013) 3593-3602. doi:10.1007/s00216-0136762-z.

[36] J. Garoz-Ruiz, A. Heras, S. Palmero, A. Colina, Development of a Novel Bidimensional Spectroelectrochemistry Cell Using Transfer Single-Walled Carbon Nanotubes Films as Optically Transparent Electrodes, Anal. Chem. 87 (2015) 6233-6239. doi:10.1021/acs.analchem.5b00923.

[37] J. Garoz-Ruiz, A. Heras, A. Colina, Direct Determination of Ascorbic Acid in a Grapefruit: Paving the Way for In Vivo Spectroelectrochemistry, Anal. Chem. 89 (2017) 1815-1822. doi:10.1021/acs.analchem.6b04155.

[38] A. Heras, A. Colina, J. López-Palacios, A. Kaskela, A.G. Nasibulin, V. Ruiz, E.I. Kauppinen, Flexible optically transparent single-walled carbon nanotube electrodes for UV-Vis absorption 
spectroelectrochemistry, Electrochem. Commun. 11 (2009) 442-445.

doi:10.1016/j.elecom.2008.12.016.

[39] T. Wang, D. Zhao, N. Alvarez, V.N. Shanov, W.R. Heineman, Optically Transparent Carbon Nanotube Film Electrode for Thin Layer Spectroelectrochemistry, Anal. Chem. 87 (2015) 96879695. doi:10.1021/acs.analchem.5b01784.

[40] J.D. Brewster, J.L. Anderson, Fiber Optic Thin-Layer Spectroelectrochemistry with Long Optical Path, Anal. Chem. 54 (1982) 2560-2566. doi:10.1021/ac00251a035.

[41] T. Kuwana, J.W. Strojek, Kinetic and mechanism studies of o-tolidine electro-oxidation using optically transparent electrodes, Discuss. Faraday Soc. 45 (1968) 134-144. doi:10.1039/df9684500134.

[42] E.E. Bancroft, J.S. Sidwell, H.N. Blount, Derivative linear sweep and derivative cyclic voltabsorptometry, Anal. Chem. 53 (1981) 1390-1394. doi:10.1021/ac00232a021.

\section{Figure1a}

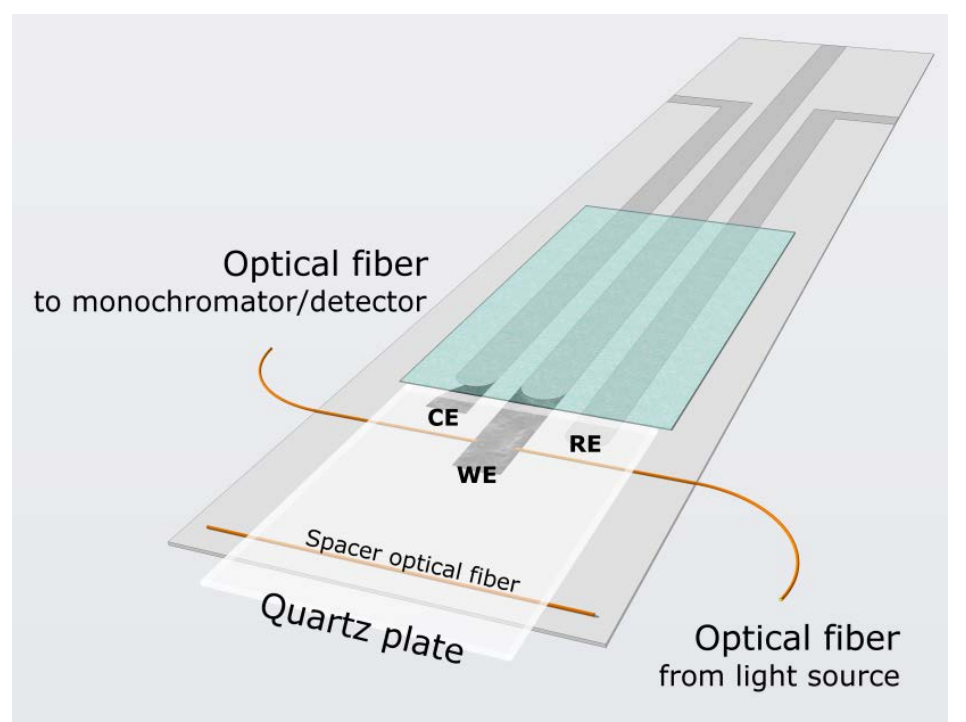

Fig. 1. (A) Illustration of the UV-Vis absorption thin-layer SEC device based on CNTs electrodes.

\section{Figure1b}




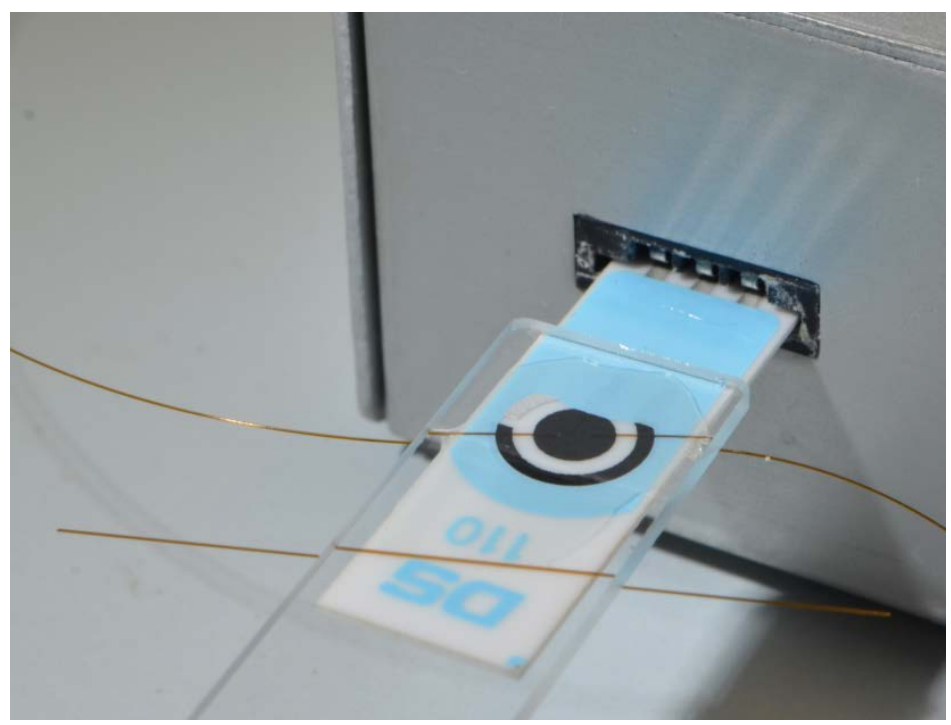

Fig. 1. (B) Photograph of the UV-Vis absorption thin-layer SEC device based on a commercial carbon SPE.

\section{Figure1c}

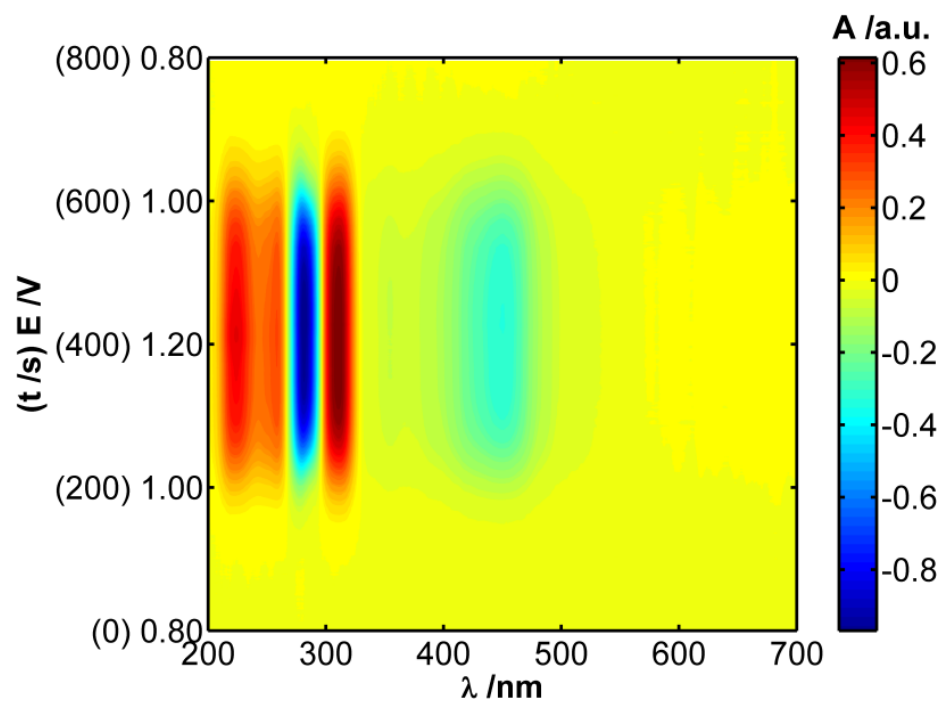

Fig. 1. (C) Spectra evolution with time/potential recorded during a cyclic voltammetry of $5 \cdot 10^{-4} \mathrm{M} \mathrm{Ru}\left(\right.$ bipy) ${ }_{3}{ }^{2+}$ in $0.2 \mathrm{M} \mathrm{KCl}$ between $+0.80 \mathrm{~V}$ and $+1.20 \mathrm{~V}$ at $0.001 \mathrm{~V} \cdot \mathrm{s}^{-1}$, using the device based on a carbon SPE. 


\section{Figure2a}

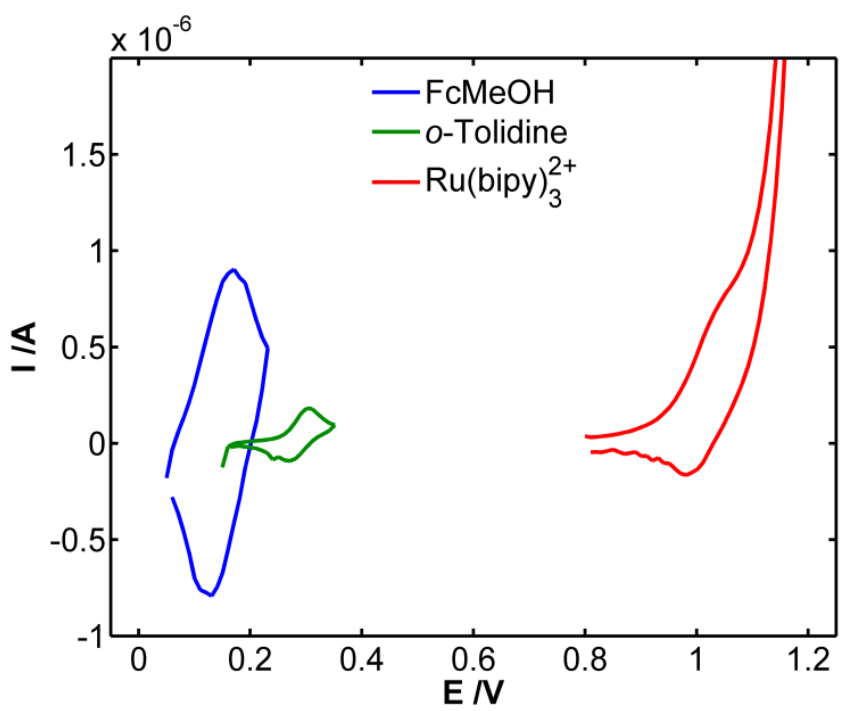

Fig. 2. (A) Cyclic voltammograms of $\mathrm{FcMeOH}, o$-tolidine and Ru(bipy) ${ }_{3}{ }^{2+}$.

Figure2b 


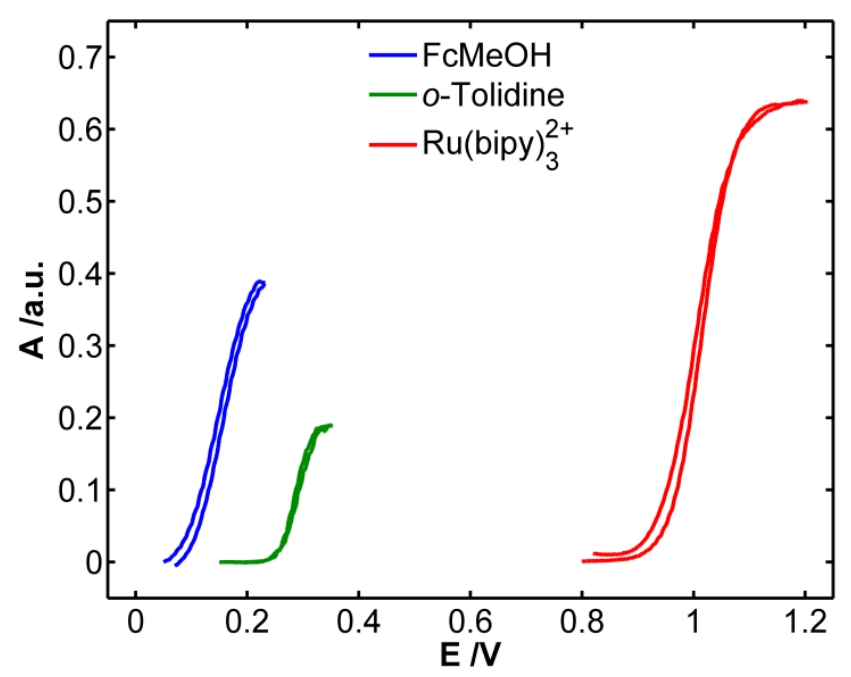

Fig. 2. (B) Cyclic voltabsorptograms of FcMeOH (282 nm), o-tolidine (437 nm) and Ru(bipy) ${ }_{3}{ }^{2+}(310 \mathrm{~nm})$. 